\title{
Simple method for quantifying viable bacterial numbers in sputum
}

\author{
A Pye, R A Stockley, S L Hill
}

\begin{abstract}
Aims-To establish a simple method of quantitative culture for determining the viable bacterial numbers present in expectorated sputum samples.

Methods-Sputum samples were homogenised with dithiothreitol, sterile saline or glass beads to determine which method recovered the greatest number of viable bacteria. Culture broths were also incubated with dithiothreitol and sampled over time to determine its effect on bacterial viability. Sputum samples homogenised with dithiothreitol were diluted in sterile saline and sampled using either standard bacteriological loops or a precision pipette to determine which method resulted in the least variation.

Results-Homogenisation of sputum using dithiothreitol increased the recovery of viable bacteria compared with sterile glass beads and/or saline, with no apparent effect on bacterial viability when incubated with culture broths. By inoculating agar plates with $10^{-3}, 10^{-4}$ and $10^{-5}$ dilutions of the homogenised sputum sample, all potential pathogens could easily be identified. A $10 \mu 1$ sample volume dispensed by precision pipette and spread with a "hockey stick" resulted in the least variation between plates (less than 16\%) and an even distribution of bacterial colonies. Numbers of viable bacteria recovered from different aliquots of individual sputum samples were generally of the same order of magnitude. Conclusions-This method represents a relatively quick and simple technique for accurately quantifying viable bacteria present in sputum samples. The use of a small portion appears to be representative of the sample as a whole.

( $F$ Clin Pathol 1995;48:719-724)
\end{abstract}

Keywords: Sputum, quantification, bacteria.

Patients with chronic lung diseases such as bronchiectasis, chronic bronchitis and cystic fibrosis regularly produce sputum from which a variety of bacterial species including Haemophilus influenzae, Streptococcus pneumoniae, Branhamella catarrhalis, Pseudomonas aeruginosa, and Staphylococcus aureus have been isolated. ${ }^{1-3}$ The isolation of many of these bacteria has been improved by the use of selective media but in general the results of sputum culture are often unreliable because of the heterogeneous nature of sputum and the sampling techniques used. Furthermore, merely noting the presence or absence of a bacterial species can be misleading particularly when monitoring the effect of antibiotic therapy where a reduction in bacterial numbers rather than eradication of the organism may have occurred, with clearance of secretions from purulent to mucoid and a clinical improvement in symptoms. ${ }^{145}$

Many of the current sputum culture techniques are based upon observations published in the $1950 \mathrm{~s}$. In recent years with the recognition that bacteria may be playing an important pathogenic role in the progression of many of the above chronic lung diseases, ${ }^{6-8}$ it has become apparent that sputum culture techniques require re-evaluation. This is particularly the case where the number of bacteria present reflects the clinical status and hence the need for, and response to, treatment. ${ }^{9}$ It has been recognised in patients with cystic fibrosis that the use of quantitative bacteriological assessment of sputum should be encouraged, firstly, to judge the significance of the bacterial species present and, secondly, to assess the therapeutic efficacy of antibiotic treatment, ${ }^{1}$ but to date this has not been extended for use in other chronic lung diseases.

Although several authors have described various methods for quantifying viable bacterial numbers in sputum, ${ }^{10-14}$ no universally accepted method has been established. The aim of the studies reported here was to establish a simple, reliable method for quantitative bacterial culture of sputum, with particular reference to homogenisation, sample volume and plate inoculation technique. The variation in bacterial numbers recovered from individual sputum samples was also investigated to determine whether sampling a small portion of the expectorated sputum gives results that are representative of the sample as a whole.

\section{Methods}

\section{SPUTUM SAMPLES}

All samples of sputum were collected from clinically stable patients with radiologically confirmed bronchiectasis who were regularly attending a specialist outpatient clinic. On waking, patients were encouraged to perform their usual postural drainage routine and then to collect their sputum into sterile universal containers over four hours. A macroscopic assessment of the collected sputum sample was made and samples were classified as being mucoid (M), mucopurulent (MP) or purulent $(\mathrm{P})$ in nature as described previously.$^{5}$

\section{HOMOGENISATION TECHNIQUE}

Eighteen sputum samples (six M, six MP and six $P$ ) were collected from individual patients and shaken manually before being weighed into four equal aliquots which were treated as 
follows: aliquot 1,10 sterile glass beads $(2 \cdot 5-$ $3.5 \mathrm{~mm}$, BDH Ltd, Poole, Dorset, UK) were added and the sample vortex mixed for five minutes; aliquot 2,10 sterile glass beads were added plus an equal volume of sterile saline $(0.9 \% \mathrm{w} / \mathrm{v}$ $\mathrm{NaCl}$ ) and vortex mixed for five minutes; aliquot 3, 10 sterile glass beads were added plus an equal volume of Sputasol (Oxoid Ltd, Basingstoke, UK; containing $100 \mu \mathrm{g} / \mathrm{ml}$ dithiothreitol) and vortex mixed for five minutes; aliquot 4 , an equal volume of Sputasol alone was added and vortex mixed for five minutes.

All four aliquots were incubated at $37^{\circ} \mathrm{C}$ for 15 minutes to aid the homogenisation process and then processed as follows: a $1 \mathrm{ml}$ aliquot of each homogenised sample was diluted in sterile saline $(0.9 \% \mathrm{w} / \mathrm{v}$ sodium chloride) to produce a dilution series of 1 in $10\left(10^{-1}\right), 1$ in $100\left(10^{-2}\right), 1$ in $1000\left(10^{-3}\right), 1$ in 10000 $\left(10^{-4}\right)$, and 1 in $100000\left(10^{-5}\right)$. The homogenised sputum sample ( 1 in 2 dilution) and the $10^{-3}, 10^{-4}$ and $10^{-5}$ dilutions were used to inoculate chocolate, blood and MacConkey agar plates. All plates were incubated at $36^{\circ} \mathrm{C}$ in an atmosphere of $5 \% \mathrm{CO}_{2}$ in air and examined for bacterial growth after 24 and 48 hours. Plates yielding between 30 and 300 colonies were counted using a manual tally counter and the viable bacterial numbers present were expressed as colony forming units per millilitre $(\mathrm{cfu} / \mathrm{ml})$ of original sputum. Aliquots treated with beads alone were initially diluted 1 in 2 to simulate the dilution factor when homogenised with saline or Sputasol.

Viable numbers of the predominant organism recovered in all 18 samples using the four homogenisation methods were compared using the Wilcoxon rank sum test. The results were also divided into the three macroscopic sputum categories ( $M, M P$ and $P$ ) and differences within the categories were compared using the Wilcoxon rank sum test.

To investigate whether Sputasol had any effect on bacterial viability, culture broths of $P$ aeruginosa, $H$ influenzae, $B$ catarrhalis, and $S$ pneumoniae were prepared in separate $5 \mathrm{ml}$ volumes of sterile brain heart infusion broth (Oxoid Ltd.). Broths for $H$ influenzae were supplemented with a final concentration of $10 \mu \mathrm{g} / \mathrm{ml}$ nicotinamide adenine dinucleotide (Sigma, Poole, Dorset, UK) and haemin (BDH Ltd.). All broths were incubated for four hours at $36^{\circ} \mathrm{C}$ to attain a logarithmic stage of growth before $100 \mu \mathrm{l}$ of broth was removed to determine the $\mathrm{cfu} / \mathrm{ml}$ present $(\mathrm{t}=0)$. Each broth was immediately divided into two $2 \mathrm{ml}$ aliquots to provide a test and control for each organism, with an equal volume of Sputasol added to the test, and an equal volume of culture broth added to the control. Broths were incubated at $37^{\circ} \mathrm{C}$ to simulate the conditions of sputum homogenisation, and test and control broths were sampled by removing $100 \mu \mathrm{l}$ after 15,30 and 90 minutes of incubation, diluting from $10^{-1}$ to $10^{-5}$ in sterile saline and plating in triplicate onto appropriate agar to determine $\mathrm{cfu} / \mathrm{ml}$ at each time point. Differences in cfu/ $\mathrm{ml}$ at $\mathrm{t}=0$ and after the 90 minute incubation for both test and control broths were compared for each of the four bacterial species using analysis of variance.
INOCULATION METHOD AND SAMPLE VOLUME Sputum samples from six patients (three $M$, one MP and two P) were homogenised with Sputasol, serially diluted in sterile saline as described earlier and inoculated in triplicate onto agar plates using two methods. Firstly, the conventional sterile loop method ${ }^{4}$ using plastic disposable bacteriological loops (Technical Services Ltd, Bury, UK) calibrated to deliver $1 \mu \mathrm{l}, 5 \mu \mathrm{l}$ and $10 \mu \mathrm{l}$ to sample all the sputum dilutions and to inoculate the entire agar surface. Secondly, dispensing $1 \mu \mathrm{l}, 5 \mu \mathrm{l}$ and $10 \mu \mathrm{l}$ of all sputum dilutions from a fixed volume precision pipette (Finnpipette, Labsystems, Basingstoke, UK) onto the centre of the agar surface and spreading the sample evenly across the entire plate using a disposable plastic spreader or "hockey stick" (Technical Services Ltd.). The viable numbers of the predominant organism recovered using the two methods and the different sample volumes were compared, together with the ease of enumerating individual colonies. The coefficient of variation $(\mathrm{CV})$ in $\mathrm{cfu} / \mathrm{ml}$ was calculated for each method.

VARIABILITY IN BACTERIAL NUMBERS WITHIN INDIVIDUAL SPUTUM SAMPLES

A total of 18 sputum samples were collected and divided as follows: six samples (five MP, one $P$ ) were shaken manually before being divided into five separate portions of $6.0 \mathrm{ml}$, $4.0 \mathrm{ml}, 2.0 \mathrm{ml}, 1.0 \mathrm{ml}$, and $0.5 \mathrm{ml}$ of the collected sample as a whole; nine samples (three $\mathbf{M}$, three MP, three $\mathbf{P}$ ) were shaken manually before being divided into six equal portions by weight; three samples were transferred to individual sterile petri dishes and were divided into mucoid and purulent portions based on macroscopic appearance as described by Chodosh ${ }^{15}$ before being divided into a total of six aliquots. For example, if a sample contained $4 \mathrm{ml}$ of mucoid secretion and $8 \mathrm{ml}$ of purulent secretion, the sample was divided into two aliquots of mucoid and four of purulent. All portions of sputum were homogenised with an equal volume of Sputasol and serially diluted as described earlier. Viable bacterial numbers were determined by removing a $10 \mu \mathrm{l}$ volume of the $10^{-3}$ to $10^{-5}$ dilutions using a precision pipette and spreading the sample across the agar surface using a sterile plastic "hockey stick". The viable numbers of the predominant organism in each portion of the divided samples were compared, and differences in its quantitative distribution throughout the portions were tested using analysis of variance. The CV of viable bacterial numbers between each of the portions for individual patients was also determined.

\section{Results}

HOMOGENISATION TECHNIQUE

The predominant organism present in all 18 samples was $H$ influenzae and in 15 of these samples the numbers recovered were of the same order of magnitude for all four treatment methods. The greatest viable numbers were recovered when sputum was treated with Sputasol (mean (SEM) 5.0 (1.0) $\left.\times 10^{8} \mathrm{cfu} / \mathrm{ml}\right)$ 
or when treated with Sputasol and sterile glass beads $\left(5 \cdot 2(1.0) \times 10^{8} \mathrm{cfu} / \mathrm{ml}\right)$, although there was no significant difference between these two treatment methods. Significantly lower viable numbers of $H$ influenzae were recovered using mechanical disruption with glass beads alone $\left(3.8(0.9) \times 10^{\mathrm{s}} \mathrm{cfu} / \mathrm{ml}\right)$ or glass beads plus saline $\left(4 \cdot 1(0 \cdot 8) \times 10^{\circ} \mathrm{cfu} / \mathrm{ml}\right)$ when compared with homogenisation with Sputasol or Sputasol plus glass beads $(\mathrm{p}<0.002)$.

A similar result was observed when the data were analysed for the three sputum categories. In the six mucoid samples there was no difference in viable numbers recovered between beads alone $\left(5 \cdot 0(1.8) \times 10^{8} \mathrm{cfu} / \mathrm{ml}\right)$ or beads plus saline $\left(5 \cdot 0(1.6) \times 10^{\circ} \mathrm{cfu} / \mathrm{ml}\right)$, with significantly higher numbers $(\mathrm{p}<0.05)$ recovered when the samples were homogenised with beads plus Sputasol $\left(6 \cdot 0(2 \cdot 1) \times 10^{8} \mathrm{cfu} / \mathrm{ml}\right)$ or Sputasol alone $\left(6 \cdot 2(2.3) \times 10^{\circ} \mathrm{cfu} / \mathrm{ml}\right) \mathrm{com}-$ pared with the other two treatment methods. In the six mucopurulent samples slightly fewer $(\mathrm{p}<0.02)$ numbers of bacteria were recovered with beads alone $\left(2.0(0.9) \times 10^{\mathrm{s}} \mathrm{cfu} / \mathrm{ml}\right) \mathrm{com}-$ pared with beads plus saline $\left(2 \cdot 4(1 \cdot 0) \times 10^{\circ}\right.$ $\mathrm{cfu} / \mathrm{ml})$. However, significantly higher numbers, compared with beads or beads plus saline, were recovered using beads plus Sputasol $(3 \cdot 0$ $\left.(1 \cdot 4) \times 10^{8} \mathrm{cfu} / \mathrm{ml}\right)$ or with Sputasol alone $(2 \cdot 7$ $\left.(1 \cdot 1) \times 10^{8} \mathrm{cfu} / \mathrm{ml}\right)(\mathrm{p}<0.01)$. In the six purulent samples there was no difference in viable numbers recovered between beads alone $(4 \cdot 4$ $\left.(1 \cdot 7) \times 10^{8} \mathrm{cfu} / \mathrm{ml}\right)$ or beads plus saline $(4.9$ $\left.(1 \cdot 7) \times 10^{8} \mathrm{cfu} / \mathrm{ml}\right)$ but significantly higher numbers were recovered with beads plus Sputasol $\left(6 \cdot 5(1 \cdot 7) \times 10^{8} \mathrm{cfu} / \mathrm{ml}\right)$ and with Sputasol alone $\left(6 \cdot 3(1.6) \times 10^{8} \mathrm{cfu} / \mathrm{ml}\right)$ when compared with the other two treatment methods $(\mathrm{p}<0.05)$.

The effect of Sputasol on viable bacterial numbers in culture broths of $P$ aeruginosa, $H$ influenzae, $B$ catarrhalis, and $S$ pneumoniae is shown in the figure. No significant difference in the recovery of viable bacteria was observed over the 90 minute study period for any of the

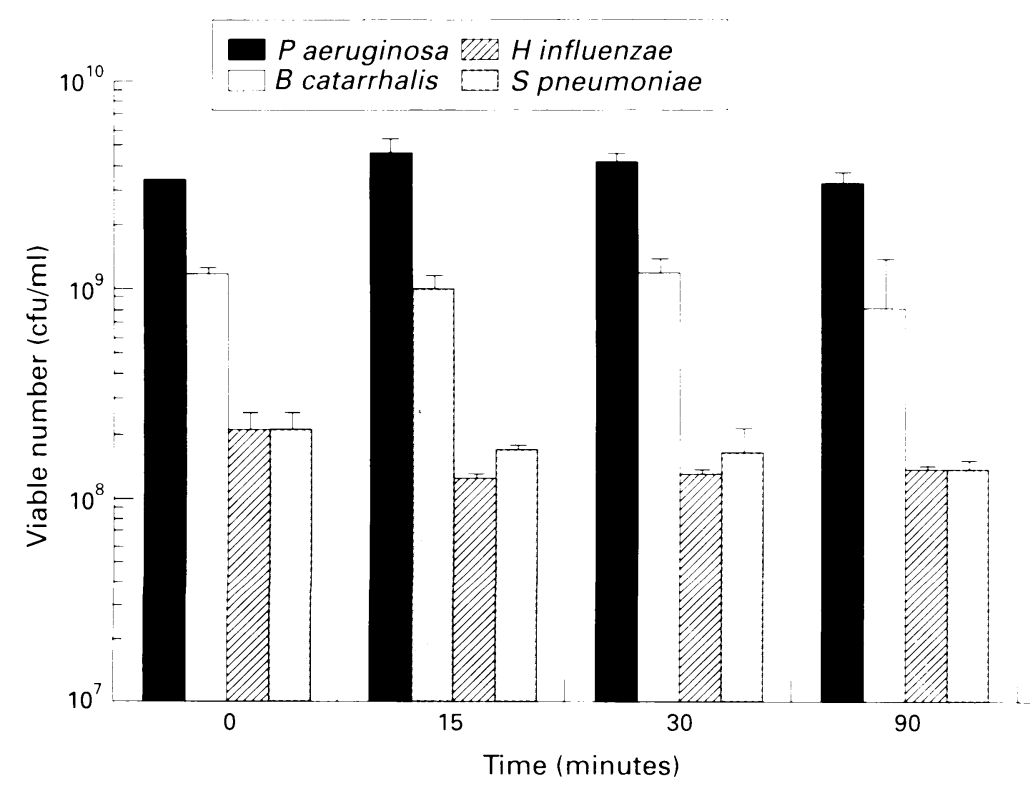

Mean (SEM) riable bacterial numbers, expressed as ifu ml, for $P$ acruginosa, $H$ influenzae, $B$ catarrhalis, and $S$ pneumoniae growing in culture broth containing an equal zolume of Sputasol and sampled over 90 minutes. four organisms investigated: $P$ aeruginosa, mean (SEM), 3.26 $(0 \cdot 07) \times 10^{\circ} \mathrm{cfu} / \mathrm{ml}$ at $\mathrm{t}=0$ and $3.21(0.33) \times 10^{\circ} \mathrm{cfu} / \mathrm{ml}$ at $\mathrm{t}=90 ;$ H influenzae, $1.17(0.08) \times 10^{\circ} \quad \mathrm{cfu} / \mathrm{ml}$ at $\mathrm{t}=0$ and 0.8 $(0.06) \times 10^{\circ} \mathrm{cfu} / \mathrm{ml}$ at $\mathrm{t}=90 ; B$ catarrhalis, $2 \cdot 13$ $(0.39) \times 10^{\circ} \quad \mathrm{cfu} / \mathrm{ml}$ at $\mathrm{t}=0$ and 1.38 $(0.06) \times 10^{\circ} \mathrm{cfu} / \mathrm{ml}$ at t $=90$; and $S$ pneumoniae, $2.16(0.4) \times 10^{\circ} \quad \mathrm{cfu} / \mathrm{ml}$ at $\mathrm{t}=0$ and 1.34 $(0 \cdot 13) \times 10^{\circ} \mathrm{cfu} / \mathrm{ml}$ at $\mathrm{t}=90$. After 90 minutes mean viable bacterial numbers were similar in the control broths: P aeruginosa, mean (SEM), $2.91(0.26) \times 10^{\circ} \mathrm{cfu} / \mathrm{ml} ; H$ influenzae, 0.92 $(0.34) \times 10^{\circ} \quad \mathrm{cfu} / \mathrm{ml} ; \quad B$ catarrhalis, 1.63 $(0.13) \times 10^{\circ} \mathrm{cfu} / \mathrm{ml}$; and $S$ preumoniae, 1.65 $(0 \cdot 5) \times 10^{\times} \mathrm{cfu} / \mathrm{ml}$.

INOCULATION METHOD AND SAMPLE VOLUME $H$ influenzae was also the predominant organism recovered from the six sputum samples used for this series of experiments, and results for the recovery of this organism using the two different inoculation methods and four sample volumes are shown in table 1 . Viable numbers of $H$ influenzae recovered when using both inoculation methods and the differing sample volumes were similar for all samples with the exception of the $5 \mu 1$ loop result for sample no. 5 (table 1). In four of the six samples (nos 1, 4,5 , and 6 ) dispensing all three volumes from a pipette resulted in less variation in viable numbers of $H$ influenzae recovered from triplicate plates (CV range $4 \cdot 4$ to $22.9 \%$ ) compared with using a bacteriological loop (CV range 16.9 to $45 \cdot 2 \%$ ). In the remaining two samples the $1 \mathrm{ml}$ volume in sample no. 2 , and the $1 \mathrm{ml}$ and $5 \mathrm{ml}$ volumes in sample no. 3 resulted in more variation using a pipette compared with the bacteriological loop (table 1). In five of the six samples (nos 1, 2, 4, 5, and 6) the lowest CV for viable numbers recovered from all triplicate plates was obtained when a $10 \mu l$ volume was dispensed from a pipette (CV range 4.4 to $15 \cdot 0 \%$ ). In the remaining sample (no. 3), although the $10 \mu$ volume dispensed from a pipette did not result in the least variation in the triplicate plates, the $\mathrm{CV}$ using this volume was only $15 \cdot 7 \%$ (table 1 ).

Plates yielding between 30 and 300 colonies were those inoculated with either the $10^{3}$, $10^{4}$ or $10^{5}$ dilutions, with the $10^{1}$ and $10^{2}$ dilutions generally showing semi-confluent growth. The numbers of colonies counted from consecutive 10-fold dilutions were approximately an order of magnitude different as expected. To recover and quantify the most common respiratory pathogens, the $10^{3} \mathrm{di}-$ lution should be plated onto chocolate and MacConkey agar, the $10^{4}$ dilution onto chocolate and blood agar, and the $10^{5}$ dilution onto chocolate agar alone.

VARIABILITY IN BACTERIAL NUMBERS WITHIN INDIVIDUAL SPUTUM SAMPLES

The viable numbers of the predominant organism recovered from six sputum samples divided into five portions of different volumes $(6.0 \mathrm{ml}$, $4.0 \mathrm{ml}, 2.0 \mathrm{ml}, 1.0 \mathrm{ml}$, and $0.5 \mathrm{ml})$ are shown in table 2. The predominant organism identified in sputum collected from these six samples was recovered in all five portions, al- 
Table 1 Mean viable numbers of $\mathrm{H}$ influenzae (cfu/ml) recovered from a range of sample volumes (1 ml, $5 \mathrm{ml}$ and $10 \mathrm{ml}$ ) of homogenised sputum dispensed using a bacteriological loop and precision pipette. The figures in parentheses represent the coefficient of variation of viable numbers of $H$ influenzae recovered from triplicate plates

\begin{tabular}{|c|c|c|c|c|c|c|}
\hline \multirow[b]{2}{*}{ Sample No. } & \multicolumn{2}{|l|}{$1 \mathrm{ml}$ volume } & \multicolumn{2}{|l|}{$5 \mathrm{ml}$ volume } & \multicolumn{2}{|c|}{$10 \mathrm{ml}$ volume } \\
\hline & Loop & Pipette & Loop & Pipette & Loop & Pipette \\
\hline $\begin{array}{l}1 \\
(\mathrm{M}) \\
2 \\
(\mathrm{M}) \\
3 \\
(\mathrm{M}) \\
4 \\
(\mathrm{MP}) \\
5 \\
(\mathrm{P}) \\
6 \\
(\mathrm{P})\end{array}$ & $\begin{array}{l}3.23 \times 10^{8} \\
(45 \cdot 2 \%) \\
2 \cdot 67 \times 10^{7} \\
(77 \cdot 9 \%) \\
3 \cdot 23 \times 10^{7} \\
(32.7 \%) \\
1 \cdot 13 \times 10^{8} \\
(34.5 \%) \\
1.45 \times 10^{8} \\
(27 \cdot 1 \%) \\
5.17 \times 10^{8} \\
(25.8 \%)\end{array}$ & $\begin{array}{l}7.97 \times 10^{8} \\
(22.1 \%) \\
4.33 \times 10^{7} \\
(92.4 \%) \\
4.03 \times 10^{7} \\
(55.4 \%) \\
1.13 \times 10^{8} \\
(13.3 \%) \\
2.39 \times 10^{8} \\
(22.9 \%) \\
7.07 \times 10^{8} \\
(21.8 \%)\end{array}$ & $\begin{array}{l}6.13 \times 10^{8} \\
(21.7 \%) \\
1.07 \times 10^{7} \\
(51.4 \%) \\
2.53 \times 10^{7} \\
(8.90 \%) \\
9.40 \times 10^{7} \\
(24.4 \%) \\
4.40 \times 10^{8} \\
(43.4 \%) \\
5.07 \times 10^{8} \\
(38.1 \%)\end{array}$ & $\begin{array}{l}8.27 \times 10^{8} \\
(14.8 \%) \\
7.00 \times 10^{7} \\
(37.4 \%) \\
4.27 \times 10^{7} \\
(11.8 \%) \\
9.70 \times 10^{7} \\
(13.4 \%) \\
1.15 \times 10^{8} \\
(10.4 \%) \\
5.40 \times 10^{8} \\
(10.6 \%)\end{array}$ & $\begin{array}{l}5 \cdot 10 \times 10^{8} \\
(17 \cdot 5 \%) \\
3 \cdot 33 \times 10^{7} \\
(62.5 \%) \\
1.07 \times 10^{7} \\
(19 \cdot 4 \%) \\
8 \cdot 70 \times 10^{7} \\
(20 \cdot 4 \%) \\
1 \cdot 11 \times 10^{8} \\
(31.8 \%) \\
2 \cdot 07 \times 10^{8} \\
(16.9 \%)\end{array}$ & $\begin{array}{l}6.80 \times 10^{8} \\
(6.5 \%) \\
7.67 \times 10^{7} \\
(15.0 \%) \\
2.53 \times 10^{7} \\
(15.7 \%) \\
6.80 \times 10^{7} \\
(4.4 \%) \\
2.45 \times 10^{8} \\
(5.86 \%) \\
5.65 \times 10^{8} \\
(5.0 \%)\end{array}$ \\
\hline
\end{tabular}

though viable numbers did show some variation, with CVs ranging from $31 \cdot 2$ to $101.9 \%$ in individual samples. In three of the samples (nos 2, 5 and 6) viable numbers were of the same order of magnitude for each of the five portions (table 2). In two of the other three samples (nos 1 and 3 ) viable numbers varied by half to one order of magnitude in one of the five portions and in the remaining sample (no. 4) two of the five portions differed by an order of magnitude, which accounted for the highest $\mathrm{CV}$ observed (101.9\%). The variability between samples showed a wide range (table 2). However, there was no major difference related to the volume sampled and variability for $1 \mathrm{ml}$ volumes was similar to that seen for $6 \mathrm{ml}$.

Table 3 shows the viable bacterial numbers of the predominant organism recovered in six aliquots of nine individual sputum samples. In seven of the nine samples (nos $1,2,4,5,6$, 7, and 9) the predominant organism was $H$ influenzae; in the remaining samples the predominant organism was $B$ catarrhalis in sample no. 3 and $P$ aeruginosa in sample no. 8 . The predominant organism was recovered in viable numbers of the same order of magnitude from each aliquot of the nine samples irrespective of the macroscopic appearance of the sample. The CV of viable numbers in the six aliquots ranged from 10.0 to $37 \cdot 2 \%$ (median $17 \cdot 2 \%$ ) in individual patient samples as shown in table 3 . No significant difference was observed when mean viable numbers for each of the six aliquots from the nine individual samples were compared (aliquot 1, mean (SEM), $3.31(2 \cdot 12) \times 10^{8} \mathrm{cfu} / \mathrm{ml} ;$ aliquot $2,4.67$ $(2.7) \times 10^{8} \mathrm{cfu} / \mathrm{ml}$; aliquot $3,4.63(2.34) \times 10^{8}$ $\mathrm{cfu} / \mathrm{ml}$; aliquot $4,4.87(2.76) \times 10^{8} \mathrm{cfu} / \mathrm{ml}$; aliquot $5,5 \cdot 12(3.00) \times 10^{8} \mathrm{cfu} / \mathrm{ml}$; and aliquot $\left.6,5.66(3.2) \times 10^{8} \mathrm{cfu} / \mathrm{ml}\right)$.

The results for viable numbers of the predominant organism recovered in the portions of three sputum samples divided according to macroscopic appearance are summarised in table 4 . In sample nos 1 and 2 the predominant organism recovered was $H$ influenzae, while in sample no. 3 it was $S$ aureus. The predominant organism present was isolated in numbers of the same order of magnitude in all six aliquots of each of the three samples, irrespective of the macroscopic appearance of the sputum (table 4). However, the CV of viable numbers in the six aliquots was higher for these three samples: $21 \cdot 2 \%, 38 \cdot 9 \%$ and $86 \cdot 1 \%$, respectively, when compared with the nine samples shaken manually before splitting into six equal aliquots, where six were less than $21 \%$ and the range was 10.0 to $37 \cdot 2 \%$ (table 3 ).

Table 2 Viable numbers (cfulml) of the predominant organism isolated from five portions of sputum from six patients divided into unequal volumes. Also shown is the mean and coefficient of variation (CV\%) for the five portions and each of the six samples

\begin{tabular}{|c|c|c|c|c|c|c|c|c|}
\hline Sample No. & Sputum & Organism & $6 m l$ & $4 m l$ & $2 m l$ & $1 \mathrm{ml}$ & $0.5 \mathrm{ml}$ & Mean (SEM) \\
\hline $\begin{array}{l}1 \\
2 \\
3 \\
4 \\
5 \\
6 \\
\text { Mean } \\
\text { CV\% }\end{array}$ & $\begin{array}{l}M P \\
M P \\
M P \\
M P \\
M P \\
P\end{array}$ & $\begin{array}{l}S \text { aureus } \\
H \text { influenzae } \\
H \text { influenzae } \\
H \text { influenzae } \\
H \text { influenzae } \\
H \text { influenzae }\end{array}$ & $\begin{array}{l}1.05 \times 10^{7} \\
4.30 \times 10^{8} \\
1.30 \times 10^{7} \\
1.92 \times 10^{8} \\
2.26 \times 10^{8} \\
1.08 \times 10^{9} \\
3.25 \times 10^{8} \\
123.4 \%\end{array}$ & $\begin{array}{l}5.70 \times 10^{6} \\
1.80 \times 10^{8} \\
6.00 \times 10^{6} \\
1.47 \times 10^{9} \\
2.20 \times 10^{8} \\
7.60 \times 10^{9} \\
1.58 \times 10^{9} \\
189.9 \%\end{array}$ & $\begin{array}{l}6.80 \times 10^{6} \\
2.00 \times 10^{8} \\
1.40 \times 10^{7} \\
1.85 \times 10^{8} \\
3.08 \times 10^{8} \\
6.40 \times 10^{9} \\
1.19 \times 10^{9} \\
215.7 \%\end{array}$ & $\begin{array}{l}3.00 \times 10^{6} \\
4.20 \times 10^{8} \\
1.70 \times 10^{7} \\
1.24 \times 10^{9} \\
3.47 \times 10^{8} \\
2.75 \times 10^{9} \\
7.56 \times 10^{8} \\
132.8 \%\end{array}$ & $\begin{array}{l}8.60 \times 10^{6} \\
1.40 \times 10^{8} \\
1.50 \times 10^{7} \\
1.29 \times 10^{8} \\
1.49 \times 10^{8} \\
1.89 \times 10^{9} \\
3.89 \times 10^{8} \\
189.9 \%\end{array}$ & $\begin{array}{ll}6.92 \times 10^{6} & (1.27) \\
2.74 \times 10^{8} & (0.63) \\
1.30 \times 10^{7} & (0.19) \\
6.43 \times 10^{8} & (2.93) \\
2.50 \times 10^{8} & (0.35) \\
3.94 \times 10^{9} & (1.29)\end{array}$ \\
\hline
\end{tabular}

Table 3 Viable bacterial numbers (cfu/ml) of the predominant organism present in six aliquots of nine sputum samples obtained from clinically stable patients with bronchiectasis

\begin{tabular}{|c|c|c|c|c|c|c|c|c|c|}
\hline \multirow[b]{3}{*}{ Sample No. } & \multicolumn{6}{|c|}{ Viable numbers } & & & \multirow[b]{3}{*}{$C V$} \\
\hline & Aliquot numb & & & & & & & & \\
\hline & 1 & 2 & 3 & 4 & 5 & 6 & \multicolumn{2}{|c|}{ Mean (SEM) } & \\
\hline $\begin{array}{l}1(\mathrm{M}) \\
2(\mathrm{M}) \\
3(\mathrm{M}) \\
4(\mathrm{MP}) \\
5 \text { (MP) } \\
6 \text { (MP) } \\
7(\mathrm{P}) \\
8 \text { (P) } \\
9 \text { (P) }\end{array}$ & $\begin{array}{r}1 \cdot 10 \times 10^{8} \\
12 \cdot 2 \times 10^{8} \\
3.16 \times 10^{8} \\
2 \cdot 21 \times 10^{8} \\
4.97 \times 10^{8} \\
2.40 \times 10^{7} \\
1.41 \times 10^{9} \\
1.45 \times 10^{8} \\
1.41 \times 10^{8}\end{array}$ & $\begin{array}{l}1.51 \times 10^{8} \\
8.10 \times 10^{8} \\
1.20 \times 10^{8} \\
1.96 \times 10^{8} \\
5.76 \times 10^{8} \\
2.46 \times 10^{7} \\
2.09 \times 10^{9} \\
1.29 \times 10^{8} \\
1.04 \times 10^{8}\end{array}$ & $\begin{array}{l}1.85 \times 10^{8} \\
9.80 \times 10^{8} \\
2.40 \times 10^{8} \\
2.39 \times 10^{8} \\
5.86 \times 10^{8} \\
3.47 \times 10^{7} \\
1.57 \times 10^{9} \\
1.64 \times 10^{8} \\
1.44 \times 10^{8}\end{array}$ & $\begin{array}{l}1 \cdot 51 \times 10^{8} \\
8 \cdot 70 \times 10^{8} \\
4 \cdot 20 \times 10^{8} \\
2 \cdot 17 \times 10^{8} \\
5 \cdot 80 \times 10^{8} \\
3 \cdot 20 \times 10^{7} \\
1 \cdot 82 \times 10^{9} \\
1 \cdot 70 \times 10^{8} \\
1 \cdot 19 \times 10^{8}\end{array}$ & $\begin{array}{l}1.34 \times 10^{8} \\
8.60 \times 10^{8} \\
2.42 \times 10^{8} \\
2.05 \times 10^{8} \\
6.30 \times 10^{8} \\
3.38 \times 10^{7} \\
2.12 \times 10^{9} \\
2.49 \times 10^{8} \\
1.34 \times 10^{8}\end{array}$ & $\begin{array}{l}1.53 \times 10^{8} \\
8.11 \times 10^{8} \\
2.60 \times 10^{8} \\
3.79 \times 10^{8} \\
6.74 \times 10^{8} \\
3.64 \times 10^{7} \\
2.45 \times 10^{9} \\
1.91 \times 10^{8} \\
1.43 \times 10^{8}\end{array}$ & $\begin{array}{l}1.47 \\
9.25 \\
2.66 \\
2.43 \\
5.91 \\
3.09 \\
1.91 \\
1.75 \\
1.31\end{array}$ & $\begin{array}{l}(0.10) \\
(0.64) \\
(0.40) \\
(0.28) \\
(0.24) \\
(0.22) \\
(0.16) \\
(0.17) \\
(0.06)\end{array}$ & $\begin{array}{l}17 \cdot 0 \% \\
17 \cdot 0 \% \\
37 \cdot 2 \% \\
28 \cdot 0 \% \\
10 \cdot 0 \% \\
17 \cdot 2 \% \\
20 \cdot 4 \% \\
24 \cdot 0 \% \\
12 \cdot 2 \%\end{array}$ \\
\hline
\end{tabular}


Table 4 Viable numbers (cfu/ml) of the predominant organism recovered from six aliquots of three sputum samples obtained from clinically stable patients with bronchiectasis which had been divided into aliquots according to the macroscopic appearance of the sputum samples

\begin{tabular}{|c|c|c|c|c|c|c|c|c|c|}
\hline \multirow[b]{3}{*}{ Sample No. } & \multirow[b]{3}{*}{ Sputum } & \multicolumn{6}{|c|}{ Viable numbers } & \multirow[b]{3}{*}{ Mean (SEM) } & \multirow[b]{3}{*}{$C V$} \\
\hline & & \multicolumn{6}{|c|}{ Aliquot number } & & \\
\hline & & 1 & 2 & 3 & 4 & 5 & 6 & & \\
\hline 1 & $\begin{array}{l}40 \% \mathrm{M} \\
60 \% \mathrm{MP}\end{array}$ & $\begin{array}{l}1.00 \times 10^{7} \\
(\mathrm{M})\end{array}$ & $\begin{array}{l}7 \cdot 90 \times 10^{7} \\
(\mathrm{M})\end{array}$ & $\begin{array}{l}4.00 \times 10^{7} \\
(\mathrm{MP})\end{array}$ & $\begin{array}{l}8.00 \times 10^{7} \\
(\mathrm{MP})\end{array}$ & $\begin{array}{l}1.20 \times 10^{7} \\
(\mathrm{MP})\end{array}$ & $\begin{array}{l}1 \cdot 15 \times 10^{7} \\
(\mathrm{MP})\end{array}$ & $3.88(1.37)$ & $86 \cdot 1 \%$ \\
\hline 2 & $\begin{array}{l}50 \% \mathrm{MP} \\
50 \% \mathrm{P}\end{array}$ & $\begin{array}{l}1.60 \times 10^{8} \\
(\mathrm{MP})\end{array}$ & $\begin{array}{l}3.50 \times 10^{8} \\
(\mathrm{MP})\end{array}$ & $\begin{array}{l}2 \cdot 23 \times 10^{8} \\
(\mathrm{MP})\end{array}$ & $\begin{array}{l}1.96 \times 10^{8} \\
\text { (P) }\end{array}$ & $\begin{array}{l}1.34 \times 10^{8} \\
\text { (P) }\end{array}$ & $\begin{array}{l}1.56 \times 10^{8} \\
(P)\end{array}$ & $2.03(0.32)$ & $38.9 \%$ \\
\hline 3 & $\begin{array}{l}60 \% \mathrm{MP} \\
40 \% \mathrm{P}\end{array}$ & $\begin{array}{l}1.90 \times 10^{8} \\
(\mathrm{MP})\end{array}$ & $\begin{array}{l}1 \cdot 84 \times 10^{8} \\
(M P)\end{array}$ & $\begin{array}{l}2 \cdot 55 \times 10^{8} \\
\text { (MP) }\end{array}$ & $\begin{array}{l}1.54 \times 10^{8} \\
(\mathrm{MP})\end{array}$ & $\begin{array}{l}1.39 \times 10^{8} \\
(\mathrm{P})\end{array}$ & $\begin{array}{l}2.09 \times 10^{8} \\
\text { (P) }\end{array}$ & $1 \cdot 89(0 \cdot 16)$ & $21 \cdot 2 \%$ \\
\hline
\end{tabular}

\section{Discussion}

The quantitative bacterial culture method described here was established following investigation of homogenisation techniques, inoculation methods and sample volumes, and has resulted in a relatively quick and reproducible method. To overcome the problem of the heterogeneous nature of sputum, it must first be liquified to produce a homogeneous, easy-to-handle sample. ${ }^{1617} \mathrm{~A}$ wide variety of agents have been used for this purpose, with dithiothreitol being the most potent. ${ }^{18}$ Based on this observation, $100 \mu \mathrm{g} / \mathrm{ml}$ dithiothreitol (contained in the commercial preparation Sputasol) was used as a chemical homogenisation agent for the studies reported here, and was compared with homogenisation using sterile glass beads. Results of quantitative bacterial culture showed that viable numbers of $H$ influenzae of the same order of magnitude were recovered for all treatment methods tested, but higher viable numbers were consistently recovered from aliquots of sputum treated with Sputasol. This increased recovery of viable bacteria was observed for all three sputum categories ( $M, M P$ and $P$ ). In addition, sputum homogenised using glass beads appeared subjectively to be more viscous, rather than less, whereas the chemical action of Sputasol generally resulted in complete liquidisation of the sample making further serial dilutions of the sample more accurate and easier to achieve.

Previous reports have suggested that chemical homogenisation of sputum may have a deleterious effect on viable bacterial numbers, ${ }^{51920}$ with Hammerschlag $e t$ al ${ }^{20}$ reporting that $50 \mu \mathrm{g} / \mathrm{ml}$ dithiothreitol inhibited the growth of $P$ aeruginosa, $S$ aureus and $H$ influenzae recovered from the sputum of patients with cystic fibrosis. The results obtained in the studies reported here, however, indicate that greater viable numbers of $H$ influenzae are recovered from sputum treated with dithiothreitol (at an equivalent final concentration), suggesting that homogenisation using this method does not appear to have a deleterious effect on the number of viable bacteria recovered. The difference between the two reports may reflect the different incubation times as the effect observed by Hammerschlag et al followed a two hour incubation period with dithiothreitol, after which time the bacteria may have been irreparably damaged. Nevertheless, whatever is responsible for the differences observed, the results obtained for bacterial culture broths incubated with Sputasol show that this agent does not appear to adversely affect bacterial viability over 90 minutes.
Most previously published quantitative bacterial culture methods have used a calibrated bacteriological loop to sample sputum and inoculate agar plates. ${ }^{101621}$ It has been shown, however, that the actual volume sampled when using a loop is dependent on a number of variables, including the angle of sampling, volume of specimen and size of the specimen container. ${ }^{22}$ In the study reported here the use of calibrated disposable loops was compared with dispensing an equivalent volume from a precision pipette and, in general, less variation in the recovery of viable bacteria was observed between triplicate plates when using a precision pipette. The greater variability in viable numbers recovered using the calibrated loop is probably because of a greater variation in the actual volume sampled when using this method. However, using a precision pipette to sample a $1 \mu \mathrm{l}$ volume also resulted in a substantial degree of variation (CV range 13.3 to $92.4 \%$ ), which probably partly relates to the inaccuracy incurred when dispensing small volumes from this instrument. Dispensing a larger volume $(10 \mu \mathrm{l})$ from the precision pipette resulted in the lowest variation in viable numbers (CV range 4.4 to $15 \cdot 7 \%$ ). Spreading the sample across the agar surface using a sterile "hockey stick" also gave a more even distribution of colonies with no area of dense growth at the point of inoculation which was often observed when using the disposable loop. This more even spread of bacterial colonies made counting easier and may have contributed to the improved accuracy.

It is widely believed that there is considerable variation in bacteria recovered from different portions of the same sputum sample following the study by Robert May in the 1950 s. $^{23}$ To date, this observation has not received further evaluation and therefore as part of these studies the variability of viable bacterial numbers within portions of individual sputum samples was investigated. When individual sputum samples were divided into six aliquots, the predominant organism present was recovered in viable numbers of the same order of magnitude, with a median $\mathrm{CV}$ between aliquots of $17 \cdot 2 \%$ (range $12 \cdot 2$ to $37 \cdot 2 \%$ ) which is comparable with that observed for the technique itself where a CV of less than $15 \cdot 7 \%$ between triplicate plates was observed using a $10 \mu \mathrm{l}$ volume (table 1). When individual sputum samples were divided into portions of unequal volume, although the predominant organism present was recovered in each aliquot, the viable numbers recovered were not always of the same order of magnitude, resulting in increased 
variability ( $31 \cdot 2$ to $101 \cdot 9 \%)$. In four of the six samples, however, the $\mathrm{CV}$ was $\leq 51 \cdot 1 \%$. In general, the results for the $6 \mathrm{ml}$ portions were not greater than those observed for the smaller volume portions, with the $6.0 \mathrm{ml}$ and $1.0 \mathrm{ml}$ portions showing similar variation in viable numbers recovered $(123.4 \%$ and $132.8 \%$, respectively). For sputum samples divided into six aliquots according to macroscopic appearance, the predominant bacterial species present was isolated in all aliquots and was recovered in similar viable numbers although a greater degree of variation was observed $(\mathrm{CV}$ range $21 \cdot 2$ to $86 \cdot 1 \%$ ) than for the nine samples divided into aliquots irrespective of macroscopic appearance (CV range of 12.2 to 37.2 $\%)$. The greatest variation $(86 \cdot 1 \%)$ was observed in the sample that was composed of mucoid and purulent portions, whereas in the other two samples, which were composed of mucopurulent and purulent portions, the $\mathrm{CV}$ was much lower $(21 \cdot 1$ and $38.9 \%$, respectively) and was comparable with that observed for the nine samples divided into aliquots irrespective of the macroscopic appearance.

The method described by $\mathrm{May}^{23}$ only sampled a small amount of unhomogenised sputum, using a bacteriological loop, and this probably explains the reason why such a wide variation in bacterial composition was found when sampling different areas of the same sputum sample. In addition, May studied sputum from patients with chronic bronchitis, where the nature of sputum is often more heterogeneous and is probably comparable with the sputum composed of mucoid and mucopurulent portions described here, where the greatest degree of variation in the viable numbers recovered was observed. However, the results obtained in the studies reported here show that when individual sputum samples are divided into aliquots of at least $0.5 \mathrm{ml}$ and homogenised with Sputasol, the viable bacterial numbers recovered are generally similar in all portions, thus sampling just one area appears to provide a true representation of the viable bacterial numbers in the sample as a whole, although it remains possible that this may not be the case for sputum specimens from chronic lung diseases other than bronchiectasis.

In conclusion, the quantitative bacterial culture method described here represents a relatively simple means of accurately determining viable bacterial numbers of the predominant organisms present in expectorated sputum samples. It differs from other quantitative methods described previously in that a $10 \mu \mathrm{l}$ sample volume of homogenised, diluted sputum is dispensed from a precision pipette and spread across the agar surface using a sterile "hockey stick". The viable bacteria present can thus be determined accurately without the need for preparing replicate plates. In addition, by using pre-measured aliquots of diluent and sampling only three dilutions $\left(10^{-3}, 10^{-4}\right.$ and $\left.10^{-5}\right)$ all major bacterial species $\left(10^{6} \mathrm{cfu} / \mathrm{ml}\right.$ or greater) can be quantified, making the technique relatively quick and easy to perform, thus overcoming the problems of previous quantitative culture techniques which were time consuming and difficult to use. The growth of discrete colonies on agar plates inoculated with diluted sputum greatly improves the identification of all potential pathogens present in the sample, without the risk of overgrowth by normal commensal flora or less fastidious organisms such as pseudomonal species. Use of this quantitative technique should greatly improve the value of sputum culture especially for monitoring the effects of antibiotic therapy and in understanding the role that bacteria play in acute infective exacerbations, and in the progression of chronic lung diseases such as bronchiectasis, chronic bronchitis and cystic fibrosis.

The authors wish to thank the General Hospital Bicentenary Appeal Fund for financial support and Mrs Esther Ford for help in the production of the manuscript.

1 Govan JRW, Doherty C, Glass S. Rational parameters for antibiotic therapy in patients with cystic fibrosis. Infection 1987;15:300-7.

2 Pang JA, Cheng A, Chan HS, Poon D, French G. The bacteriology of bronchiectasis in Hong Kong, investigated by protected catheter brush and bronchoalveolar lavage Am Rev Respir Dis 1989;139:14-17.

3 Butt HL, Saunders NA, Clancy RL, Sutherland DC, Cripps $\mathrm{AW}$, Hensley MJ, et al. Bacterial colonisation of the respiratory tract in chronic bronchitis. Aust NZ $\mathcal{F}$ Med 1990; 20:35-8.

4 Stockley RA, Hill SL, Morrison HM. Effect of antibiotic treatment on sputum in bronchiectatic outpatients in a stable clinical state. Thorax 1984;39:414-19.

5 Hill SL, Morrison HM, Burnett D, Stockley RA. Short term response of patients with bronchiectasis to treatment with amoxycillin given in standard or high doses or by inhalation. Thorax 1986;41:559-65.

6 Cole PJ. A new look at the pathogenesis and management of persistent bronchial sepsis: a "vicious circle" hypothesis and its logical therapeutic connotations. In: Davies RJ, ed. Strategies for the management of chronic bronchial sepsis. Oxford: Medicine Publishing Foundation, 1984:1-20.

7 Stockley RA. Chronic bronchitis: the antiproteinase/proteinase balance and the effect of infection and corticosteroids. In: Fick RBJ, ed. Inflammatory disorders of the airways. Vol 9 in the series Clinics in Chest Medicine. airvays. Vol 9 in the series Clinics

8 Koch C, Hoiby N. Pathogenesis of cystic fibrosis. Lancet 1993;341:1065-9.

9 Gallis HA. Acute bronchitis and acute exacerbations of chronic bronchitis: The role of new antimicrobial agents. Infect Dis Clin Pract 1994;3:81-6.

10 Kilbourn JP, Campbell RA, Grach JL, Willis MD. Quantitative bacteriology of sputum. Am Rev Respir Dis 1968; 98:810-18.

11 Wilson MJB, Martin DE. Quantitative sputum culture as a means of excluding false positive reports in routine microbiology laboratory. $\mathcal{\exists}$ Clin Pathol 1972;25:697-700.

12 Bartlett JG, Finegold SH. Bacteriology of expectorated sputum with quantitative culture and wash technique comtum with quantitative culture and wash technique com-
pared to transtracheal aspirates. Am Rev Respir Dis 1978; pared to transt

13 Wong K, Roberts MC, Owens L, Fife M, Smith AL. Selective media for the quantitation of bacteria in cystic fibrosis sputum. $\mathcal{F}$ Med Microbiol 1984;17:113-19.

14 Currie DC, Higgs E, Metcalfe S, Roberts DE, Cole PJ Simple method of monitoring colonising microbial load in chronic bronchial sepsis: pilot comparison of reduction in colonising microbial poa with antibiotics in colonising microbial 830-6.

15 Chodosh S. Sputum cytology in chronic bronchial disease. Adv Asthma Allergy 1977;4:8-27.

16 Monroe PW, Muchmore HG, Felton FG, Pirtle JK. Quantitation of microorganisms in sputum. Appl Microbiol 1969; 18:214-20.

17 Pirtle JK, Monroe PW, Smalley TK, Mohr JA, Rhoades ER. Diagnostic and therapeutic advantages of serial quantitative cultures of fresh sputum in acute bacterial pneumonia. Am Rev Respir Dis 1969;100:831-8.

18 Hirsch SR, Zastrow JE, Kory RC. Sputum liquefying agents: a comparative in vitro evaluation. $\mathcal{F}$ Lab Clin Med 1969; 74:346-53.

19 Medici TC, von Graevenitz A, Shang H, Bohni E, Wall M. Gram stain and culture of morning and $24 \mathrm{~h}$ sputum in the Gram stain and culture dogma disputed. Eur Respir $\mathcal{f}$ 1988;1:923-8.

20 Hammerschlag MR, Harding L, Macone A, Smith AL, Goldman DA. Bacteriology of sputum in cystic fibrosis: Goldman DA. Bacteriology of sputum in cystic fibrosis: Microbiol 1980;11:552-7.

21 Kalin M, Lindberg AA, Tunevall G. Etiological diagnosis of bacterial pneumonia by Gram stain and quantitative of bacterial pneumonia by Gram stain and quantitative
culture of expectorates. Scand f Infect Dis 1983;15:153-60.

22 Albers AC, Fletcher RD. Accuracy of calibrated-loop transfer. $\mathcal{F}$ Clin Micnebiol 1983;18:40-2.

23 May JR. The bacteriology of chronic bronchitis. Lancet 1953;ii:534-7. 